\title{
Evolution of coarctation of the aorta in intrauterine life
}

\author{
LINDSEY D ALLAN, DIANE C CRAWFORD, M TYNAN \\ From the Department of Paediatric Cardiology, Guy's Hospital, London
}

SUMMARY The echocardiographic appearances in a case of coarctation of the aorta, first suspected at 21 weeks of intrauterine life, changed progressively during this time. Early right ventricular hypertrophy and increasing aortic arch hypoplasia were evident and suggest the possible sequence of evolution of the coarctation in this case.

There has long been discussion on the aetiology of coarctation of the aorta. Craigie in 1841 was the first to note the proximity of the ductus arteriosus to the site of coarctation and to suggest that the lesion of coarctation was related to traction during constriction of the ductus. ${ }^{1}$ This theory was later expanded by Skoda in 1855, who suggested that the aortic narrowing was caused by the extension of obliterating ductal tissue into the aorta. ${ }^{2}$ Histological studies have substantiated this suggestion ${ }^{3}$ by demonstrating a sling of ductal tissue around the aorta in specimens of coarctation. The contribution of isthmal haemodynamics to the development of aortic coarctation was first postulated by Rokitansky in $1852^{4}$ and later enlarged by Bremer in 1948.5 These authors suggested that diminution of blood flow through the aortic isthmus produced isthmal narrowing. Rudolph et al in 1972 proposed that an alteration in orientation of the entry of the ductus arteriosus into the descending aorta produced a jet from the ductus which indented the posterior aortic wall. ${ }^{6}$ This anatomical variation was exaggerated when ductal closure occurred producing the coarctation lesion. This theory was extended by Shinebourne and Alseed, who noted the absence of coarctation in lesions with reduced pulmonary blood flow in utero. ${ }^{7}$

It has been suggested that a decrease in isthmal blood flow consequent on the coarctation may produce the isthmal hypoplasia commonly found in cases of coarctation in infancy. The frequency of ventricular septal defects found in these patients has led to speculation that the ventricular septal defect causes the flow alterations. More recently, it has been found that ventricular septal defects are commonly perimembranous with aortic override or of the malignment type. It is suggested that the associated

Requests for reprints to Dr Lindsey D Allan, Department of Paediatric Cardiology, Guy's Hospital, London SE1 9RT. posterior displacement of the outlet portion of the ventricular septum diminishes aortic flow by directing flow preferentially towards the pulmonary artery ${ }^{8}$ in intrauterine life. Nevertheless, not all patients with coarctation have ventricular septal defects.

We recently examined a case of coarctation of the aorta first presenting at 21 weeks' gestation and màde some unexpected findings, which we consider contribute to the discussion on the aetiology of coarctation of the aorta.

\section{Case report}

The patient's mother was referred for fetal echocardiography because of congenital heart disease in her first child. The first child had presented at 1 week of age in shock. Coarctation of the aorta with arch hypoplasia was found and successfully corrected surgically. At 18 weeks' gestation in the second pregnancy fetal echocardiography showed normal cardiac connexions, but because of poor quality pictures she was examined again at 21 weeks' gestation. At this time the following echocardiographic findings were noted: right ventricular hypertrophy (Fig. 1); a normal pulmonary outflow tract, pulmonary valve, and main pulmonary artery, and ductus arteriosus; and a patent good size aortic arch (Fig. 2). The aortic arch views, however, suggested a possible discrete coarctation and poststenotic dilatation. The right ventricular hypertrophy was consistently obvious throughout pregnancy at 26, 30 , and 34 weeks' gestation, but on the lasst examination it was impossible to visualise the complete aortic arch. Only the ascending part of the aortic arch could be seen. Mild left ventricular hypertrophy developed towards term. Postnatally the echocardiogram showed severe arch and isthmal hypoplasia with poststenotic dilatation of the descending aorta beyond a coarctation (Fig. 2b). A small perimembranous ventricular 


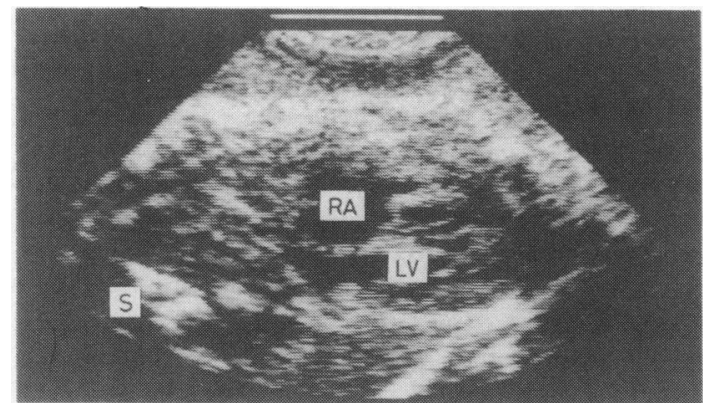

Fig. 1 Cross sectional echocardiogram of the fetal heart in the four chamber view showing the fetal thorax and a dilated and hypertrophied right ventricle. $R A$, right atrium; $L V$, left ventricle; $S$, spine.

septal defect was also seen. There was no aortic override. This defect was small on angiography, with a shunt ratio of $1.7: 1$ on oximetry. Angiography confirmed the echocardiographic findings of the aortic arch anatomy. The neonate underwent surgical arch reconstruction on the second day in life, but the anatomy was found to be very difficult to correct. Despite supportive measures the patient died four weeks after operation.

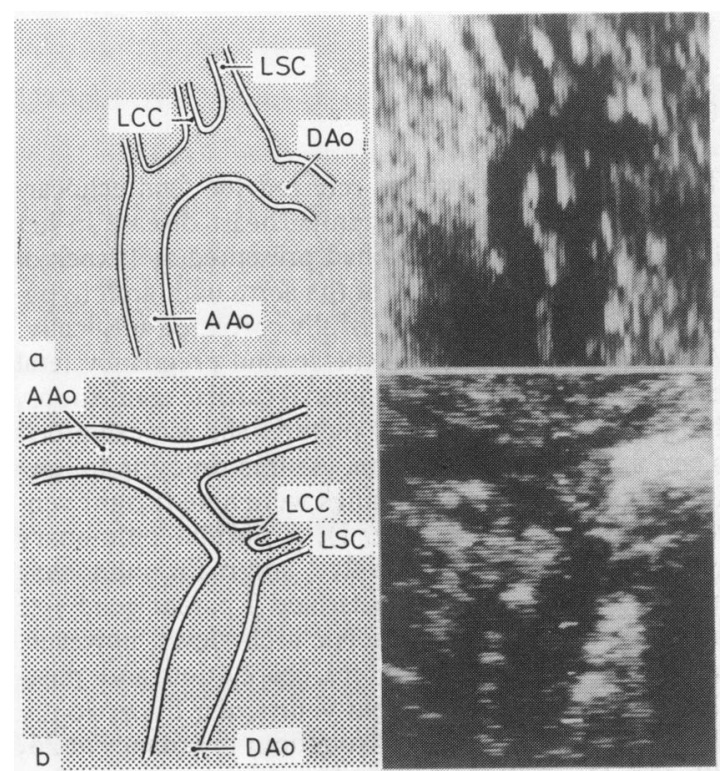

Fig. 2 Diagrams and cross sectional echocardiograms showing the arch of the aorta (a) in the 21 week fetus with the head and neck vessels arising from it and (b) after birth. (a) Just distal to the left subclavian artery (LSC) there is an area of narrowing followed by dilatation. (b) After birth the distal arch and isthmus is very narrow with prominent poststenotic dilatation. DAo, descending aorta; AAo, ascending aorta; LCC, left common carotid (artery).

\section{Discussion}

There are two points of interest in this case to those concerned in interpreting the fetal echocardiogram. Firstly, it was obvious from early pregnancy that this fetal heart was abnormal. Secondly, the anatomy of the defect changed during intrauterine life. Discrete coarctation was strongly suspected at 21 weeks' gestation because of the combination of the suspicion of poststenotic dilatation in the arch, the convincing right ventricular dilatation and hypertrophy, and the family history of coarctation, but the appearance of the aortic arch anatomy suggested that surgery would produce a good result. Nevertheless, by term the aortic arch anatomy had changed to become so hypoplastic that a poor surgical result was expected. If the arch and isthmal hypoplasia resulted from diminished blood flow through these segments this reduction in flow must have been secondary to the distal obstruction presented by the coarctation. That the obstruction was severe as early as 21 weeks is suggested by the fact that intracardiac abnormalities-namely, right ventricular dilatation and hypertrophy-were present at that time. This finding suggests that right ventricular output was greater than left ventricular output. This could be accounted for by a decrease in blood flow from the right atrium to the left atrium across the foramen ovale due to increased left ventricular end diastolic pressure, and therefore increased left atrial pressure, as a result of increased left ventricular afterload presented by the coarctation. Furthermore, this increased afterload may have increased the flow from the left ventricle to the right ventricle via the ventricular septal defect. It is unlikely that the ventricular septal defect by itself had any aetiological role in the development of the coarctation since it was small and no malalignment of the outlet septum was present. ${ }^{8}$

Studies in chronically instrumented fetal lambs suggest that aortic isthmal blood flow contributes little to descending aortic and placental blood flow. ${ }^{9}$ Nevertheless, the findings in this case that discrete coarctation can result in right ventricular volume overload indicate that in the normal human fetus flow through the aortic isthmus may, in relative and absolute terms, be appreciable.

It is certain in this case that the coarctation was not a postnatal phenomenon associated with ductus closure. The coarctation was evidently not secondary to the reduction in aortic arch and isthmal hypoplasia as a result of inappropriate streaming. Although a sling of ductus tissue cannot be excluded as the anatomical substrate for the discrete coarctation, it appears that its presence alone rather than its muscular contraction would be responsible for the coarctation.

To our knowledge this sequence of the evolution of 
coarctation of the aorta has not been described previously in the human fetus. We consider that it is of importance to report this case since it shows, firstly, that discrete coarctation of the aorta is an abnormality that may be found in prenatal life and, secondly, that isthmal hypoplasia is an acquired lesion developing after the primary lesion is evident.

\section{References}

1 Craigie D. Instance of obliteration of the aorta beyond the arch, illustrated by similar cases and observations. Edinburgh Medical and Surgical foumal 1841; 56: 42762.

2 Skoda J. Protokoll der Sections_-Sitzung fur Physiologie and Pathologie. Wochenblatt der Zeitschrift der KK Gesellschaft der Aetzte in Wien 1855; 1: 720.
3 Wielenga G, Dankmeijer J. Coarctation of the aorta. $\mathcal{F}$ Pathol Bacteriol 1968; 95: 265-74.

4 Rokitansky $C$ von. A manual of pathologic anatomy. London: The Sydenham Society, 1852; vol 4: 298-304.

5 Bremer JL. Coarctation of the aorta and the aortic isthmuses. Arch Pathol 1948; 45: 425-34.

6 Rudolph AM, Heymann MA, Spitznas U. Hemodynamic considerations in the development of narrowing of the aorta. Am $\mathcal{F}$ Cardiol 1972; 30: 514-25.

7 Shinebourne EA, Alseed AM. Developmental explanation for absence of coarctation in conditions with reduced pulmonary flow from birth [Abstract]. Br Heart $\mathcal{F}$ 1973; 35: 866.

8 Smallhorn JF, Anderson RH, Macartney FJ. Morphological characterisation of ventricular septal defects associated with coarctation of aorta by cross-sectional echocardiography. Br Heart f 1983; 49: 485-94.

9 Rudolph AM. Congenital diseases of the heart. Chicago: Year Book Medical Publishes, 1974: 332. 